\title{
Eqüidade e política de saúde: algumas reflexões sobre o Programa Saúde da Família
}

\author{
Equity and health policy: some reflections \\ on the Family Health Program in Brazil
}

Mônica de Castro Maia Senna 1

\footnotetext{
1 Departamento de Serviço Social, Universidade Federal Fluminense. Travessa Washington Luiz 317, São Gonçalo, RJ 24210-020, Brasil. marcossenna@uol.com.br
}

\begin{abstract}
This article focuses on key elements contributing to the public social policy debate, specifically from the perspective of promoting distributive justice. The reference is the Family Health Program in Brazil and its relation to recent changes in national health policy and the literature on the issues of equity and social justice. This concern is due to recent changes in social interventions by the Brazilian state, where targeting assumes a central place in the reform process. Specifically concerning health policy, the issue of equity has gained visibility, linked to the discussion on the profile of health expenditures. One of the central aspects in this context lies in the debate between notions such as the regressive and inequitable nature of targeted measures and programs, on the one hand, and the expanded perspective of access by what have traditionally been socially excluded sectors, on the other. The debate between such perspectives highlights the controversies concerning the effectiveness of health measures, equity, and the distributive concept of social justice, with the latter as the central discussion in this study.
\end{abstract}

Key words Health Policy; Equity; Social Justice; Family Health

Resumo Este artigo busca trazer alguns elementos para o debate acerca das políticas públicas de corte social, no que tange à perspectiva de promoção de justiça distributiva. Toma por referência o Programa Saúde da Família (PSF), articulando as recentes alterações na política nacional de saúde com a literatura que trata as questões de eqüidade e justiça social. Tal interesse se justifica em virtude das recentes inflexões no padrão de intervenção do Estado brasileiro na área social, onde a focalização assume um lugar central na agenda das reformas. No campo da política de saúde em especial, o tema da eqüidade ganha visibilidade articulada à discussão em torno do perfil dos gastos no setor. Um dos aspectos centrais neste contexto reside no debate que polari$z a$, de um lado, noções como o caráter regressivo e iníquo de ações e programas focais e, de outro lado, a perspectiva ampliação de acesso de setores sociais tradicionalmente excluídos. O debate entre estas perspectivas traz para discussão as polêmicas em torno da efetividade das ações de saúde, da eqüidade e da concepção distributiva de justiça social, sendo esta a discussão central deste trabalho.

Palavras-chave Política de Saúde; Eqüidade; Justiça Social; Saúde da Família 


\section{Introdução}

Uma das questões mais recorrentes nas discussões em torno do Programa Saúde da Família (PSF), implantado pelo Ministério da Saúde (MS) em âmbito nacional a partir de 1995, diz respeito ao processo de focalização promovido por este. Talvez porque inicialmente a definição da implantação do programa priorizasse as áreas de risco segundo o Mapa da Fome (Pelliano, 1993), do Instituto de Pesquisa Econômica Aplicada (IPEA) e/ou porque sua emergência se deu num contexto de crise e racionalização dos gastos em saúde, e/ou ainda devido à priorização das ações de prevenção e promoção da saúde, baseadas em baixa incorporação tecnológica, o fato é que algumas análises sobre o PSF (Misoczky, 1994; Paim, 1996) tendem a identificá-lo como uma simplificação da atenção à saúde, um sistema de saúde pobre para os pobres.

É certo que o PSF emerge num contexto de restrição e racionalização dos gastos em saúde, decorrentes da implementação de medidas de ajuste estrutural prescritas pelas agências multilaterais, sobretudo o Fundo Monetário Internacional (FMI) e o Banco Mundial. A agenda de reformas proposta por estas agências baseia-se no diagnóstico da inadequação dos gastos brasileiros em saúde, que seriam excessivos e não atingiriam as regiões e os grupos sociais mais pobres. Ao mesmo tempo, o Banco Mundial critica o modelo de assistência, assentado no cuidado hospitalar ineficaz, na especialização da atenção ambulatorial, na rápida incorporação de procedimentos de alta tecnologia e no pouco investimento nas ações preventivas e de promoção à saúde (World Bank, 1993).

O mérito desta abordagem é reconhecer que uma das características mais marcantes das políticas sociais brasileiras, e entre elas a de saúde, tem sido o privilegiamento dos grupos sociais mais favorecidos em detrimento dos segmentos de maior vulnerabilidade social, caracterizando aquilo que Ramos (2000) denomina de focalização espúria.

Nessa direção, a década de 90 é marcada pela adoção de estratégias institucionais destinadas a garantir que os programas sociais atinjam os segmentos mais vulneráveis. Num contexto marcado pela implantação de medidas de ajuste estrutural da economia e de reforma do Estado, ganha força a perspectiva de racionalização dos gastos públicos, onde a eficiência e a eqüidade aparecem como elementos centrais, traduzidos na focalização dos mais pobres como alvo prioritário das ações governamentais. Dentro desse quadro, o PSF é visto por alguns como uma medida fortemente impregnada por seu caráter racionalizador, que reserva ao Estado a função restrita de provedor dos serviços básicos de saúde, direcionados a grupos populacionais pobres e marginalizados.

Para os formuladores e gestores do PSF, no entanto, o programa tem se constituído em uma estratégia para a reorientação e reorganização do modelo de atenção à saúde no Brasil (MS, 1998). Esta concepção parte do entendimento de que as inovações introduzidas no sistema de saúde nos últimos anos, com a implantação do Sistema Único de Saúde (SUS), têm logrado resultados pouco perceptíveis na estruturação dos serviços de saúde, sobretudo por não promover mudanças significativas no modelo assistencial. Como constatam estes atores, após uma década de implantação do SUS, ainda é grande o contingente populacional, sobretudo os mais pobres, com dificuldades de acesso à assistência médica. Nesse sentido, o PSF traria, em seu bojo, a preocupação em promover o acesso destes setores anteriormente excluídos, voltando-se prioritariamente para os grupos sociais mais vulneráveis.

O debate entre essas perspectivas tem o mérito de trazer para discussão as polêmicas em torno da efetividade das ações de saúde, da eqüidade e da concepção distributiva de justiça social. Esta é a preocupação central que norteia o presente trabalho. Busca-se aqui, a partir da literatura que trata as questões de eqüidade, justiça e política social, especialmente no âmbito do setor saúde, trazer elementos que permitam estabelecer, ainda que preliminarmente, um roteiro para análise do PSF no que tange a seu potencial de incorporação de segmentos sociais vulneráveis e de promotor da eqüidade $\mathrm{e}$ da justiça social no interior da política de saúde.

Convém ressaltar que esta não é uma tarefa simples, dadas tanto a complexidade que envolve os conceitos de eqüidade e justiça social quanto a ainda incipiente tradição analítica das políticas de saúde sob este viés. Não se pretende aqui resolver os impasses e as lacunas que perpassam a temática, mas sim uma aproximação inicial com algumas das principais questões circunscritas a este campo.

\section{Políticas sociais, justiça e eqüidade: uma primeira aproximação}

A temática da eqüidade vem ocupando lugar de relevância na discussão das políticas sociais nas duas últimas décadas (Almeida et al., 1999; Berlinguer, 1999).

As recentes transformações que vêm se operando no âmbito das economias capitalistas, a 
profunda crise fiscal que atravessa os Welfare States e a quebra dos laços de solidariedade social erguidos ao longo do século XX fornecem, ao lado de outros aspectos, as condições propícias para a revisão do papel do Estado, especialmente no que diz respeito a seu padrão de intervenção social, onde a eqüidade se configura como um dos eixos centrais.

Na América Latina, o perfil da política social sofre uma profunda inflexão a partir da introdução do plano de ajuste estrutural da economia e de reforma do Estado, com a adoção da perspectiva de racionalização do gasto público (Diniz, 1997). Entre as teses mais difundidas está a que associa os altos níveis de inflação, a falta de crescimento econômico e a ineficiência e ineficácia das ações estatais ao aumento desenfreado dos gastos públicos. Neste contexto, uma das características mais marcantes do processo é a tensa conciliação dos objetivos macroeconômicos de estabilização com propostas de reformas sociais voltadas para a melhoria da eficiência e da eqüidade.

No que pesem os condicionantes mais amplos, decorrentes da dinâmica do contexto internacional, não se pode afirmar que as recentes mudanças introduzidas no padrão de relação Estado/sociedade no Brasil sejam um mero reflexo da nova ordem mundial. Como ressalta Diniz (1997), além da dimensão externa, é preciso considerar os fatores internos, relacionados ao esgotamento simultâneo do modelo de desenvolvimento vigente no país até fins dos anos 70, de seus parâmetros ideológicos e do tipo de intervenção estatal responsável por sua implementação, dentro de um quadro mais geral de reestruturação da ordem política.

Assim, nos anos 80, num contexto de transição democrática, reforçam-se expectativas de formatação de uma nova institucionalidade para as políticas sociais, com vistas ao resgate da imensa dívida social acumulada em décadas de exclusão e à ampliação dos direitos sociais. Nas palavras de Draibe (1997), tratava-se de fazer com que a democracia política pudesse se fazer acompanhar de sua base indispensável: a democracia social fundada em maior eqüidade.

Na avaliação dessa autora (Draibe, 1999), a agenda reformista dos anos 80 , no entanto, esbarrou nas mesmas contradições e indefinições do movimento político em que se inscreveu, ainda que mudanças significativas tenham sido introduzidas, das quais se destacam a valorização do princípio do direito social e a tendência à universalização do acesso dos programas sociais. No plano institucional, a descentralização, a transparência dos processos decisórios e a ampliação da participação social fo- ram identificados como sinônimos de democratização.

Ainda para Draibe, um segundo ciclo de reformas ganha corpo a partir da segunda metade dos anos 90, pautado pela complexa agenda de estabilização, reformas institucionais e consolidação democrática. Uma série de medidas e inovações institucionais são implantadas, buscando conciliar, de um lado, as exigências de adequação do padrão do gasto social aos objetivos macroeconômicos e, de outro, a promoção de maior eqüidade e justiça social. Assim, é sob um contexto de crise da capacidade fiscal e regulatória do Estado que se destacam medidas de racionalização dos gastos governamentais, visando melhor desempenho dos programas sociais e maior eficiência e eficácia das ações.

Dentro desse quadro, ganha força a perspectiva de que mais do que a insuficiência de recursos, o que caracteriza a ação governamental no Brasil é a má distribuição dos recursos existentes, que acabam não atingindo os grupos sociais mais vulneráveis. Ao se considerar o montante do gasto social brasileiro, comparativamente a outros países, observa-se que o mesmo não é insuficiente mas ineficiente (Rocha, 2001). Ao mesmo tempo, verifica-se que são os segmentos menos pobres dentre os pobres, sobretudo aqueles com maior poder de vocalização, os que proporcionalmente mais se apropriam dos serviços e benefícios sociais prestados (Ramos, 2000). Nessa direção, a focalização das políticas sociais nos grupos mais vulneráveis é defendida como forma de promover o acesso desses setores aos programas e serviços sociais.

Embora haja um relativo consenso quanto ao diagnóstico da ineficiência e ineficácia dos gastos públicos, os temas da eqüidade e da focalização têm suscitado forte polêmica. De um lado, situam-se posições que associam a focalização à perspectiva de restrição de direitos a partir da instauração de um cardápio mínimo de ações a serem desenvolvidas pelo Estado, apenas para a população mais pobre. De outro lado, encontram-se algumas análises que salientam a possibilidade de a focalização se constituir numa alternativa atraente para fazer face ao quadro de extrema pobreza e desigualdades sociais no Brasil, à medida que estabelece prioridades de acesso dos segmentos mais vulneráveis aos programas sociais.

Em termos gerais, é possível afirmar que o debate em torno da focalização das políticas sociais está extremamente relacionado à análise dos diferentes critérios adotados na alocação de recursos e na seleção dos beneficiários. Lindblom (1980) chama a atenção para que, 
embora essas escolhas sejam subsidiadas por informações de ordem técnica, elas devem ser compreendidas enquanto decisões políticas, como resposta a distintos interesses dos diversos atores sociais presentes na arena decisória.

Na mesma direção, Elster (1992) considera o importante papel que possuem os atores sociais ao influenciar a seleção de procedimentos e critérios específicos para alocação de recursos escassos. Ao mesmo tempo, este autor chama a atenção para o contexto na qual tais decisões são tomadas, identificando que os critérios e mecanismos adotados em situações de escolhas trágicas diferem sistematicamente daquelas usadas em escolhas não trágicas.

Tais escolhas encontram-se mesmo na base da definição do conceito de política social. Santos (1989:37) propõe chamar de política social a "toda política que ordene escolhas trágicas segundo um princípio de justiça consistente e coerente". No entanto, este mesmo autor salienta que à medida que o estabelecimento de princípios absolutos é incompatível com a idéia de democracia e que existem diferentes e até mesmo divergentes princípios de justiça social, resulta ser impossível a escolha de um princípio de justiça consistente e coerente, sendo essa a trágica condição da política social. Nessa perspectiva, a formulação de critérios para desenhar ou avaliar políticas sociais é, no dizer do autor, um "permanente experimento com o imprevisível" (Santos, 1989:51).

O que se quer aqui salientar é a complexidade do tema da eqüidade, ainda mais profunda frente a um quadro social marcado pelos níveis de desigualdades sociais como no caso brasileiro. O tratamento dessas desigualdades impõe, na ótica da justiça social, a definição técnica e política de prioridades com base nos valores que regem as sociedades, envolvendo a definição de quanto será distribuído e para quem será distribuído. Assim, menos do que um problema de escassez de recursos, o conceito de justiça social envolve a maneira segundo a qual benefícios e encargos, ganhos e perdas são distribuídos entre os membros de uma sociedade, como resultado do funcionamento de suas instituições (Figueiredo, 1997).

Em termos gerais, pode-se dizer que as abordagens contemporâneas em torno do tema da justiça social (Rawls, 1997; Sen, 1997; Walzer, 1983), no que pesem suas divergências, centram-se na valorização da noção de eqüidade como igualdade no alcance de objetivos finais, bem como no reconhecimento explícito de fatores determinantes das diferenças existentes na sociedade, que dizem respeito a aspectos biológicos, sociais e político-organizacionais.
No debate contemporâneo, é forte a idéia de que a desigualdade é algo desejável. A questão chave parece residir na perspectiva de que resultados eqüitativos pressupõem redistribuições desiguais de recursos, produzidas por ajustes efetuados em função dos fatores acima mencionados, determinantes das desigualdades existentes. Aqui, torna-se necessário distinguir diferença de diversidade. Enquanto a diversidade é determinada por fatores alheios à vontade humana ou resultado das vontades individuais, aquilo que é considerado socialmente injusto envolve questões éticas, morais e políticas, referindo-se a diferenças indesejáveis e, portanto, passíveis de intervenção através das políticas dos diversos setores, inclusive o de saúde (Almeida et al., 1999). Nesse contexto, a focalização assume o sentido de ação afirmativa ou discriminação positiva, como proposto por Rawls (1997), a partir da instauração de uma seletividade dos potenciais beneficiários da política, de forma a ampliar o acesso econômico, social e cultural dos segmentos sociais que realmente precisam.

\section{Eqüidade e saúde: reflexões em torno de uma política}

No campo da saúde, a conceituação de eqüidade tem sido objeto de amplo debate, englobando várias dimensões e estimulando a discussão sobre sua operacionalização, seja para a busca dos determinantes das desigualdades em saúde, seja para formulação de políticas e prioridades a serem implementadas com vistas tanto à diminuição do impacto dos diferenciais sociais na saúde, como para a elaboração de instrumentos e indicadores para o monitoramento dos processos de reforma dos sistemas de saúde (Almeida et al., 1999).

Em linhas gerais, pode-se dizer que a literatura sobre o tema tem apontado que o termo eqüidade refere-se a diferenças que são desnecessárias e evitáveis, além de consideradas injustas (Whitehead, 1992). O termo iniqüidades em saúde assume, assim, uma dimensão ética e moral. Nessa perspectiva, se determinadas diferenças individuais ou grupais, sobretudo as decorrentes de variações biológicas naturais, não devem ser tomadas como iniqüidades, no sentido acima abordado, há um certo consenso de que são desnecessárias e injustas aquelas diferenças em saúde determinadas por exposição a condições de vida e trabalho estressantes e doentias; acesso inadequado a serviços públicos essenciais, entre eles os de saúde; comportamentos que podem causar danos à saúde 
quando a liberdade de escolha do estilo de vida é restrita, entre outros aspectos (Whitehead, 1992).

Para essa autora, o objetivo das políticas de eqüidade seria, assim, reduzir ou eliminar diferenças em saúde resultantes de fatores considerados ao mesmo tempo evitáveis e injustos. Tais políticas seriam dirigidas tanto às raízes dos problemas, diminuindo riscos diferenciados, como à promoção de políticas de saúde que respondessem às necessidades de saúde criadas justamente por aquelas iniqüidades. Assim, Whitehead aponta que as políticas nacionais de saúde, planejadas para a população como um todo, não podem pretender preocupar-se da mesma forma com a saúde de todos se o impacto mais importante sobre a saúde/doença se faz sentir nos grupos mais vulneráveis da sociedade.

Também Almeida et al. (1999) relacionam eqüidade em saúde com justiça social, sendo as desigualdades consideradas justas ou injustas conforme as distintas interpretações das determinações da estratificação social. Para essas autoras, as iniqüidades estão fundadas nas relações sociais que determinam as chances da população obter acesso aos recursos materiais e aos produtos sociais resultantes daqueles recursos.

Nessa direção, cabe uma distinção entre eqüidade em saúde e eqüidade nos cuidados de saúde, à medida que suas determinações não são as mesmas. Eqüidade em saúde referese às necessidades em saúde que são socialmente determinadas e que transcende o escopo das ações dos serviços da área, à medida que os cuidados de saúde são apenas um entre os inúmeros fatores que contribuem para as desigualdades em saúde. Nesse sentido, como afirmam Giovanella et al. (1996), a ação isolada dos serviços de saúde não é suficiente para resolver o conjunto das iniqüidades em saúde, mas certamente pode contribuir para reduzi-las.

Já em relação à eqüidade no uso de serviços de saúde, é preciso considerar que utilização dos serviços, além de influenciada pelo perfil de necessidades de cada grupo populacional, também está condicionada por inúmeros outros fatores, internos e externos ao setor, relacionados tanto à oferta dos serviços quanto às preferências e possibilidades dos usuários. Assim, "para além da determinação biológica e social das necessidades, são considerados como fatores explicativos de uso de serviços aqueles relacionados com a efetiva implementação da política de saúde" (Almeida et al., 1999:11).

É este último aspecto aquele que nos interessa aqui de forma central.
Especialmente no campo da política de saúde, a preocupação com o tema da eqüidade ganha expressiva visibilidade a partir dos anos 90, articulada ao debate em torno do perfil dos gastos no setor, marcado por um desenfreado aumento dos gastos em saúde (Berlinguer, 1999).

No período, vários países do mundo iniciam a implantação de profundas reformas de seus sistemas de saúde (Almeida, 1996; Mendes, 1996), visando, sobretudo, novas alternativas para solucionar o quadro de crise de financiamento. Inúmeros esforços são empreendidos a fim de reduzir custos e equalizar os dilemas postos pela ampliação da demanda em saúde, tendo em vista a redução da capacidade de captar recursos e financiar as ações de saúde por parte da maioria dos estados nacionais.

Apesar da variedade de contextos e das especificidades dos processos de constituição e operação dos sistemas nacionais de saúde de cada país, pode-se afirmar que, em geral, as propostas para a área da saúde aglutinam-se em torno de quatro pontos fundamentais, constituindo a denominada agenda global da saúde (Viana \& Dal Poz, 1998):

a) separação das funções de provisão e financiamento das ações de saúde;

b) inclusão de mecanismos de mercado por meio da competição administrada;

c) ênfase na efetividade clínica;

d) mudanças na concepção de saúde e no papel dos usuários nos sistemas de saúde.

No Brasil, para além desse cenário de reforma do Estado e de controle do gasto público, é preciso salientar as inovações introduzidas nas duas últimas décadas como decorrentes também de fatores internos ao próprio setor, potencializados por sua dinâmica própria e pelo processo de implementação do SUS.

Assim, cabe destacar que as reformas do sistema de saúde no Brasil dos anos 80 , se circunscrevem no movimento mais amplo de redemocratização do país e de ampliação da cidadania, onde a saúde constitui item importante na denúncia dos efeitos perversos do padrão de intervenção estatal consolidado ao longo dos anos, marcado por seu caráter centralizado, burocratizado, privatista e excludente. Fruto de uma ampla mobilização de diferentes setores da burocracia da saúde e da sociedade civil organizada - o denominado movimento sanitário - a reforma do setor saúde ganha impulso com a inscrição, na Constituição Federal de 1988 (Brasil, 1988), dos princípios e diretrizes da implantação do SUS. A universalização do acesso, enquanto uma das diretrizes do SUS, ao lado da descentralização e da participação popular, configuram uma in- 
flexão no modo predominante de produção de políticas sociais no Brasil, possibilitando romper com o padrão meritocrático característico do nosso sistema de proteção social.

É preciso, no entanto, destacar, como o fazem Almeida et al. (1999), que a inclusão de princípios de eqüidade na formulação das políticas de saúde não se acompanha da implementação automática de políticas que resultem em melhores níveis de eqüidade na prestação de serviços de saúde. Nessa direção, Draibe (1999) ressalta que a agenda de reformas no campo social depara-se, a partir da metade da década de 90, com um ambiente político muito complexo, perpassado pelo ajustamento econômico, pela complementação das reformas institucionais e pelo processo de consolidação da democracia. Assim, em que pese o inequívoco avanço da reforma da política de saúde na sua dimensão organizacional, vários problemas e desafios se interpõem, dos quais a autora destaca: as distorções e ineficiências do investimento, acarretando a implantação incompleta de redes intermediárias e básicas de serviços, o que sobrecarrega e compromete a efetividade do sistema hospitalar; a ineficiência e principalmente a ineficácia dos recursos; um modelo assistencial fundado na livre demanda, do qual estão ausentes princípios de adscrição de clientela e identificação de porta de entrada; formas antiquadas e inadequadas de organização $e$ gestão do sistema e de suas unidades organizacionais.

De fato, muitas produções teóricas em torno das políticas de saúde no Brasil têm destacado os impasses na implementação do SUS. Identificam que as recentes alterações no processo de reformulação do sistema de saúde brasileiro, sobretudo a partir de 1995, são pautadas pela perspectiva de racionalização dos gastos públicos, decorrentes da implementação das medidas de ajuste estrutural prescritas pelo Banco Mundial.

Em linhas gerais, as análises sobre o rebatimento das concepções, diretrizes e prescrições das agências multilaterais no setor saúde no Brasil, reafirmam o caráter altamente negativo que tais medidas assumem no perfil de atenção à saúde. Partem do pressuposto de que a adoção de tais orientações traz como impacto a progressiva redução no financiamento do setor, com a deterioração da rede física de serviços, a incapacidade de regulação por parte do Estado e a falta de compromisso frente às inúmeras carências de uma população profundamente desgastada pelas difíceis condições em que vive. Ao mesmo tempo, o alargamento de inúmeras propostas de focalização, preconi- zando um sistema público de saúde para os pobres e excluídos, é encarado como uma tendência racionalizadora, de contenção de gastos sociais, que põe em cheque a universalidade do direito à saúde, ao instaurar a noção de cesta básica para o setor.

Todavia, parece ser necessário relativizar e problematizar noções como o caráter regressivo e iníquo de ações e programas focais, à medida que a focalização tende a assumir um caráter altamente positivo ao se constituir uma condição necessária de garantia de acesso aos setores sociais excluídos. Nessa perspectiva, o grande desafio, salienta Barros (1996), está em compatibilizar o estabelecimento de prioridades sem adotar mecanismos de restrição de direitos sociais, como é o caso da definição de uma cesta básica para o setor.

É nesse contexto que se deve situar a discussão em torno da eqüidade no interior do PSF. O PSF se depara com o dilema entre a perspectiva de racionalização dos gastos e a busca de eqüidade e justiça social. Essa discussão remete, de um lado, ao contexto no qual se dá sua formulação, marcado pela introdução de uma série de inovações na política de saúde brasileira e, de outro, à forma como o programa vem sendo implementado nos diversos municípios, o que tende a conferir contornos diversificados em cada arena local.

\section{Reflexões em torno do Programa Saúde da Família}

O debate sobre focalização $\mathrm{x}$ discriminação positiva no interior do PSF e, portanto, sobre a perspectiva de promoção de maior eqüidade da política de saúde, remete inicialmente à problematização do contexto no qual esse é formulado, à medida que o PSF não se constitui uma iniciativa isolada mas se situa no interior de um elenco de medidas de reforma do setor nos anos 90 .

De fato, a segunda metade dos anos 90 tem como características da política de saúde a implementação de novos programas, ações regulatórias e modalidades de alocação de recursos, visando aumentar os níveis de eqüidade e eficácia do SUS. Essas medidas configuram-se num momento em que se busca promover a tensa conciliação entre objetivos macroeconômicos de estabilização, com metas de reformas sociais teoricamente voltadas para a melhoria da eficiência e da eqüidade. Esta conjuntura condicionou de forma importante a agenda das políticas governamentais e o próprio tratamento das questões econômicas e sociais, ain- 
da que seu impacto tenha se diferenciado nas diversas políticas setoriais.

No caso da saúde, pode-se dizer que as principais medidas reformistas nessa época centram-se basicamente nos seguintes aspectos (Draibe, 1999):

a) diversificação das fontes e critérios de transferência de recursos;

b) aceleração do processo de descentralização setorial;

c) focalização das ações básicas e da população carente;

d) reorganização do aparato regulador do Estado.

Nesse contexto, o PSF integra uma conjunto de medidas de reorganização da atenção básica na perspectiva, conforme apontam os documentos do MS, de se constituir uma das estratégias de reorientação do modelo de atenção à saúde da população no âmbito do SUS (MS, 1998). A adoção do PSF parte do reconhecimento de que as iniciativas de introdução de mudanças substantivas no setor saúde, a partir da implantação do SUS, apesar de seus avanços, têm resultados pouco perceptíveis na estruturação dos serviços de saúde, exatamente por não promover alterações significativas no modelo assistencial. Assim, para o MS, o programa pressupõe muito mais uma inversão do modelo de atenção à saúde do que uma simples mudança, configurando uma importante inovação programática.

O PSF tem como marco uma reunião entre técnicos do MS e os secretários municipais, em dezembro de 1993, congregando atores das várias regiões do país, de forma a romper com o confinamento das experiências de agentes comunitários e saúde da família às regiões Norte e Nordeste. Pode-se dizer que o Programa de Agentes Comunitários de Saúde (PACS) e suas experiências exitosas, sobretudo no Estado do Ceará, constituem as plataformas para implantação do PSF no país. Assim, em 1994, mas com expressão nacional somente em 1995, surge o PSF enquanto instrumento de reorganização do SUS, sendo definida sua implantação em áreas de risco, de acordo com o Mapa da Fome (Viana \& Dal Poz, 1998).

O estímulo financeiro do MS para implantação do PSF, segundo a parcela variável do Piso de Atenção Básica (MS, 1996) tem, desde 1998, efetivamente contribuído para a expansão do programa em todo o país, o que remete à definição quanto ao estabelecimento de prioridades e critérios das áreas para implantação do projeto para o nível local. Todavia, para Almeida et al. (1999), a implementação deste mecanismo foi acompanhada de uma série de re- gulamentações ministeriais, que acabaram fortalecendo o caráter focalizador da proposta ao privilegiar o número de equipes implantadas e não o aumento da cobertura, como previsto inicialmente. Apesar disso, a definição das áreas prioritárias pelo nível local pode contribuir enormemente para a o estabelecimento de prioridades e de princípios de justiça local, tal como pensado por Elster (1992), promovendo uma discriminação positiva a favor dos grupos mais vulneráveis da população.

Por outro lado, é preciso considerar que os municípios brasileiros têm sua tradição política assenta sobre o clientelismo e o paternalismo, podendo, dessa maneira, contribuir para que o PSF se configure muito mais em um mecanismo de barganha política envolvendo prefeitos, vereadores e a população do que um instrumento de promoção da eqüidade. De fato, análises sobre o processo recente de descentralização das políticas sociais no Brasil, têm ressaltado características dos níveis locais as mais diversas, que vão desde a capacidade econômica, grau de desenvolvimento e perfil de distribuição de renda até competência técnica, capacidade de governança e capital cívico, entre outros fatores. Somente estudos empíricos que se debrucem sobre o nível local, podem efetivamente contribuir para o conhecimento dos critérios (e interesses) envolvidos na implementação do programa e do tipo de focalização que está sendo realizado pelo mesmo.

Quanto ao desenho do PSF, tem-se que, em linhas gerais, cada equipe é formada por um médico generalista, dois auxiliares de enfermagem e seis agentes comunitários de saúde, devendo cobrir cerca de 4.500 habitantes e referenciar-se a uma unidade básica de saúde, que assegura o acesso do paciente na rede do SUS. A unidade de saúde da família trabalha com uma definição de território de abrangência, e cada equipe é responsável por uma área de residências de 600 a 1.000 famílias, variação que leva em conta as diversidades regionais. Para Draibe (1999), a adscrição territorial da clientela, juntamente com a opção pela unidade familiar, constituem-se duas das principais inovações do PSF que se não representam um avanço do SUS, são pelo menos uma correção de suas insuficiências.

As estratégias de visita domiciliar e de busca ativa, aliadas ao acompanhamento das famílias das áreas de abrangência, vêm de encontro à necessidade apontada por Vasconcelos (1999), de apoio intensivo a famílias vivendo em situações de crise que colocam em risco a vida de seus membros. Para este autor, os recentes estudos sobre a família brasileira têm 
ressaltado a existência de algumas famílias nas classes populares, que vivem situações especiais de risco (pais doentes, desempregados, com conflitos conjugais intensos, envolvimento em atividades ilícitas e perseguidas pela polícia, dependência de drogas, distúrbios mentais, etc.) que as tornam incapazes de articular minimamente os cuidados de seus membros e por isso necessitam de atenção diferenciada do Estado para garantir os direitos de cidadania das crianças, idosos e deficientes físicos ali presentes. Iniciativas nesta direção têm sido promovidas em alguns municípios brasileiros e embora Vasconcelos (1999) avalie que, em geral, elas prestem uma atenção ainda conservadora, porque presa a uma cultura tutelar que nega autonomia da família, tais iniciativas têm o mérito de potencializar a adoção de políticas mais equânimes. Assim, essa modalidade de intervenção se faz necessária pela constatação mais do que difundida de que famílias em situação mais precária tendem a ficar à margem dos serviços que orientam seu atendimento pela demanda espontânea, promovendo, deste modo, o acesso daqueles setores populacionais excluídos do sistema de saúde e ao mesmo tempo os mais vulneráveis.

Uma primeira avaliação sobre o PSF aponta para o impacto positivo do programa em áreas com grande déficit de serviços básicos de saúde, sobretudo na Região Nordeste do país. Todavia, um dos grandes desafios do programa se refere a seu impacto nas grandes regiões metropolitanas, onde, ao menos em tese, há uma oferta mais estruturada de serviços de saúde e onde se concentra um expressivo contingente populacional com elevado índice de pobreza urbana e ao mesmo tempo extremamente heterogênea.

De igual importância, outro grande desafio do programa diz respeito à sua capacidade de integração com o restante do sistema de saúde, de forma a redefinir qualitativamente o modelo de atenção à saúde, como pretendido por seus formuladores, mostrando que não é apenas uma proposta de atenção simplificada e barata para áreas pobres e rurais do país. Fica aqui a perspectiva de que o PSF possa se constituir em um mecanismo de focalização dentro da universalização de direitos promovida pelo SUS, trazendo o grande desafio de compatibilizar o estabelecimento de prioridades sem adotar mecanismos de restrição de direitos sociais, como seria o caso da definição de uma cesta básica para o setor.

\section{Considerações finais}

As últimas linhas deste trabalho se destinam a ressaltar que o conteúdo aqui apresentado se constitui numa primeira aproximação com a temática. Pretendeu-se, assim, menos um tratamento aprofundado do tema e mais a sistematização de alguns pontos que permitam refletir sobre a focalização promovida pelo PSF e seu impacto em termos de promover a eqüidade no interior da política de saúde. Muitas das questões aqui mapeadas merecem um estudo mais profundo e ricas contribuições analíticas podem surgir de investigações sobre a temática, baseadas em pesquisas empíricas solidamente fundamentadas, estando aqui um roteiro introdutório para esta incursão.

Este artigo buscou ressaltar a complexidade que envolve o tema da eqüidade e da justiça social no âmbito do PSF. Essa complexidade se aprofunda em face das grandes heterogeneidades regionais, sociais, econômicas, políticas e administrativas que marca a história brasileira. Nesse sentido, a focalização assume o caráter de inclusão de grandes parcelas da população tradicionalmente alijadas do acesso a um mínimo de garantias sociais. No entanto, é imperativo que as ações focais estejam integradas a uma política mais ampla que forneça suporte social, garanta direitos universais e que permita aos diferentes grupos sociais o desenvolvimento de suas capacidades. Caso contrário, tais ações acabam por reproduzir desigualdades e reforçar a segmentação social.

Ainda é recente o processo de implementação do PSF, sobretudo se levarmos em conta sua implantação nos municípios. Isto não impede, no entanto, que esforços analíticos sejam desenvolvidos, na perspectiva de contribuir para o debate acerca dos limites e alcances do programa quanto a universalizar e focalizar os segmentos prioritários, ultrapassando as abordagens restritas e homogêneas que não consideram as pluralidades locais. 


\section{Agradecimentos}

A autora agradece os comentários e contribuições dos professores Rosana Magalhães e Gilberto Hochman, bem como aos pareceristas anônimos da revista.

\section{Referências}

ALMEIDA, C.; TRAVASSOS, C.; PORTO, S. \& BAPTISTA, T., 1999. A Reforma Sanitária Brasileira: Em Busca da Eqüidade. Research in Public Health, Technical Papers 17. Washington, DC: Organização Pan-Americana da Saúde.

ALMEIDA, C., 1996. Novos modelos de atenção à saúde - Bases conceituais e experiências de mudança. In: Política de Saúde e Inovação Institucional: Uma Agenda para os Anos 90 (N. R. Costa \& J. M. Ribeiro, org.), pp. 69-98, Rio de Janeiro: Escola Nacional de Saúde Pública, Fundação Oswaldo Cruz.

BARROS, E., 1996. Política de saúde no Brasil: A universalização tardia como possibilidade de construção do novo. Ciência \& Saúde Coletiva, 1:5-17.

BERLINGUER, G., 1999. Eqüidade, seletividade e assistência à saúde. Lua Nova, 47:73-103.

BRASIL, 1988. Constituição da República Federativa do Brasil. Brasília: Senado Federal.

DINIZ, E., 1997. Em busca de um novo paradigma: A reforma do Estado no Brasil dos anos 90. In: Crise, Reforma do Estado e Governabilidade: Brasil 1985 - 1995 (E. Diniz, org.), pp. 175-202, Rio de Janeiro: Editora FGV.

DRAIBE, S., 1997. Uma nova institucionalidade das políticas sociais? Reflexões a propósito da experiência latino-americana recente de reforma dos programas sociais. São Paulo em Perspectiva, 11: 3-21.

DRAIBE, S., 1999. As políticas sociais nos anos 1990. In: Brasil: Uma Década em Transição (R. Baumann, org.), pp. 101-142, Rio de Janeiro: Editora Campus/Comisión Económica para América Latina y el Caribe.

ELSTER, J., 1992. Justice Local. How Institutions Allocate Scarce Goods and Necessary Burdens? New York: Russell Sage Foundation.

FIGUEIREDO, A. C., 1997. Princípios de justiça e avaliação de Políticas. Lua Nova, 39:73-103.

GIOVANELLA, L.; DRUMOND, J.; SKABA, M.; SÁ, V. \& OLIVEIRA, R., 1996. Eqüidade em saúde no Brasil. Saúde em Debate, 49/50:13-22.

LINDBLOM, C., 1980. The Policy-Making Process. New Jersey: Prentice-Hall Foundations.

MENDES, E. V., 1996. Uma Agenda para a Saúde. São Paulo: Editora Hucitec.

MISOCKSY, M. C., 1994. A medicina de família, os ouvidos do príncipe e os compromissos do SUS. Saúde em Debate, 42:40-44.
MS (Ministério da Saúde), 1996. Norma Operacional Básica do SUS. NOB-1/SUS/96. Brasília: MS.

MS (Ministério da Saúde), 1998. Saúde da Família: Uma Estratégia para a Reorientação do Modelo Assistencial. Brasília: Coordenação de Saúde da Comunidade, Secretaria de Assistência à Saúde, Ministério da Saúde.

PAIM, J., 1996. Políticas de saúde no Brasil ou recusando o apartheid sanitário. Ciência \& Saúde Coletiva, 1:18-20.

PELLIANO, A. M. T. M. (org.), 1993. O Mapa da Fome: Subsídios à Formulação de uma Política de Segurança Alimentar. Rio de Janeiro: Instituto de Pesquisa Econômica Aplicada.

RAWLS, J., 1997. Uma Teoria da Justiça. São Paulo: Martins Fontes

RAMOS, C. A., 2000. Programas Sociais, Trajetória Temporal do Acesso e Impacto Distributivo. Texto para Discussão 771. Rio de Janeiro: Instituto de Pesquisa Econômica Aplicada.

ROCHA, S., 2001. Alguns Consensos sobre a Pobreza no Brasil. Rio de Janeiro: Escola Nacional de Saúde Pública/Fundação Oswaldo Cruz. (mimeo.)

SANTOS, W. G., 1989. A trágica condição da política social. In: Política Social e Combate à Pobreza (S. H. Abranches, W. G. Santos \& M. A. Coimbra, org.), pp. 33-63, Rio de Janeiro: Jorge Zahar.

SEN, A., 1997. An Essay on Entitlement and Deprivation. Oxford: Clarendon Press.

VASCONCELOS, E. M., 1999. A priorização da família nas políticas de saúde. Saúde em Debate, 53:6-19.

VIANA, A. L. \& DAL POZ, M. R., 1998. A reforma do sistema de saúde no Brasil e o Programa de Saúde da Família. Physis - Revista de Saúde Coletiva, 8: 11-48.

WALZER, M., 1983. Spheres of Justice - A Defense of Pluralism and Equality. New York: Basic Books.

WHITEHEAD, M., 1992. The concepts and principles of equity and health. International Journal of Health Services, 22:429-445.

WORLD BANK, 1993. World Development Report. Washington, DC: World Bank.

Recebido em 7 de maio de 2002

Versão final reapresentada em 29 de agosto de 2002

Aprovado em 11 de setembro de 2002 